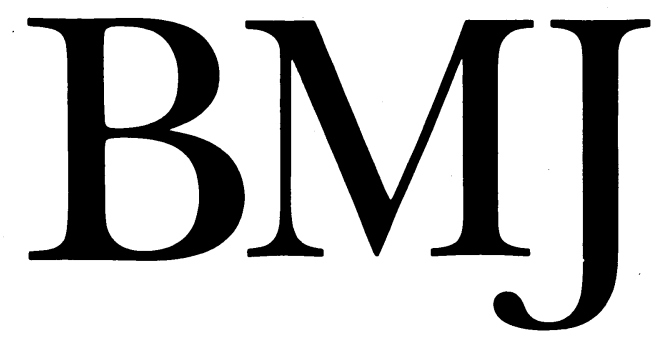

\title{
In search of the unknown primary
}

\author{
Some may benefit from treatment
}

Most patients with cancer present with an obvious primary site of their disease, but in a few no primary is apparent even after investigation. These patients have always presented clinical challenges. How far should investigations be taken if a fatal outcome is likely and the tests are unpleasant? What treatments should be used? Recent advances in oncology have made the management of these patients more taxing. Elaborate new imaging techniques are expensive. New drug treatments such as effective chemotherapy for lymphoma and germ cell tumours and biological treatment still work only in a few diseases, and the drugs may be toxic. Although it is important that patients should not miss out on effective treatment, the problems of choosing those who will benefit are considerable, and for most patients the outlook is still poor. ${ }^{1}$

When the initial histological diagnosis is poorly differentiated, undifferentiated, or anaplastic cancer further information may come from specialised pathological studies, including immunocytochemistry, electron microscopy, and karyotyping. In future, in situ hybridisation for nucleic acids will contribute to this process. The outcome of these analyses varies between centres, but one to two thirds of patients will have non-Hodgkin's lymphomas, which may be cured by chemotherapy. ${ }^{23} \mathrm{~A}$ few patients have melanoma, sarcoma, or neuroendocrine or germ cell tumours; most of the rest have carcinomas.

If the diagnosis is carcinoma the doctor must decide what investigations are justified to seek a primary site and which groups of patients should receive anticancer drugs if a primary has not been identified. The arguments against a lengthy, invasive, and sometimes uninformative series of investigations in the search for an often untreatable primary are well recognised, and there is now general acceptance of-if not always strict adherence to-the strategy of directing investigations according to the need to identify only those tumours for which effective treatment is available. ${ }^{+}$

The group of carcinomas that are considered to be worth identifying are those for which treatments either are simplefor example, hormonal-or can afford long term survival, or both. They include cancers of the breast and ovary in women, prostatic cancer in men, thyroid cancer, and small cell lung cancer.

Series vary widely in the minimum assessment undertaken before the search for the primary site is abandoned. It generally includes a complete history and physical examination, analysis of urine and examination of stools for occult blood, full blood count, basic biochemistry, and chest radiography. Additional studies to identify the treatable tumours are mammography and some form of pelvic imaging in women; measurement of the serum markers for prostatic cancer in men (prostate specific antigen and prostatic acid phosphatase); and measurement of the serum concentrations of the germ cell markers $\alpha$ fetoprotein and the $\beta$ subunit of human chorionic gonadotrophin. Abdominal computed tomography is sometimes included, and in one series it identified the primary site in one third of cases. ${ }^{5}$ Its value, however, is primarily in confirming the presence of untreatable pancreatic and other intra-abdominal tumours, thereby averting more invasive investigations. Further diagnostic procedures may be justified in selected patients on the basis of the clinical pattern and the results of the initial tests.

When the histological diagnosis is well differentiated or moderately differentiated adenocarcinoma and the above investigations give negative results necropsy studies suggest that the elusive primary is most often in the lung or gastrointestinal tract. ${ }^{67}$ It is the failure of available systemic treatments to influence survival in patients with these tumours that has discouraged the indiscriminate use of the usually invasive investigations required for their identification. Despite the promise of recent advances in the treatment of colorectal ${ }^{89}$ and gastric ${ }^{10}$ cancer additional evidence is required before systematic radiological and endoscopic evaluation of the gastrointestinal tract can be routinely recommended in these patients.

Even after careful, appropriate, and detailed investigation more than half these patients will still lack a precise diagnosis. Who should receive drug treatment? If all patients are given chemotherapy on an empirical basis, the regimens usually being based on doxorubicin or cisplatin, the response rates are in the order of $20-30 \%$, with little to choose between the various regimens. ${ }^{11}$ Responses tend to be short lived and are often at the expense of substantial toxicity; there is no evidence of an overall survival benefit. In one study with a response rate of $42 \%$ the median survival remained a disappointing 18 weeks. ${ }^{12}$

In a few well defined clinical situations the outlook may be brighter. Women presenting with metastatic disease in axillary nodes are very likely to have an occult breast cancer and may benefit from the appropriate treatment. Women with malignant ascites or predominantly peritoneal disease can survive long term after chemotherapy for ovarian cancer. ${ }^{13}$ Squamous carcinoma in a high or mid-cervical node commonly results from a primary tumour of the head, or neck, 
and thorough evaluation by an ear, nose, and throat specialist is mandatory as surgery with radiotherapy cures some of these patients. ${ }^{14}$ Similarly, squamous tumours in the inguinal lymph nodes should prompt a careful search for perianal or genital primaries and treatment for these.

A small but important group of patients with responsive tumours has been identified by Hainsworth and colleagues. ${ }^{15}$ They report a $56 \%$ response rate (including $22 \%$ complete responses) to combination chemotherapy based on cisplatin in patients with poorly differentiated carcinoma or adenocarcinoma with one or more of the following features: age less than 50; tumours affecting primarily midline structures (the mediastinum and retroperitoneum), lungs, or lymph nodes; increased serum $\alpha$ fetoprotein or $\beta$ subunit of human chorionic gonadotrophin concentrations; clinical evidence of rapid tumour growth; and tumour very responsive to previous radiotherapy or chemotherapy. They reported that $13 \%$ of their patients were alive and free of disease five years after treatment. Young patients with disease mainly in lymph nodes seemed to have the best outcomes.

The same group also reported a $78 \%$ response rate and some long term survivors among patients with poorly differentiated carcinoma with neuroendocrine features on electron microscopy (dense core vesicles) or immunocytochemical staining. ${ }^{16}$ Small cell lung cancers and carcinoid tumours were excluded from this series. Unlike most adults with neuroendocrine diseases (for example, islet cell tumours and paragangliomas) the patients had rapidly progressive diseases. This entity is rare but important therapeutically.

For patients who fall into subgroups known to respond to treatment the argument for a trial of appropriate treatment is compelling. Specific drug treatment for the larger number with well differentiated or moderately differentiated adenocarcinoma in whom the primary site is not established is not mandatory and must be judged by the doctor for the individual patient in consultation with the patient and his or her family. For many, symptomatic care alone is indicated, but some patients should receive a more active approach. Although low, the expected response rate to chemotherapy is not substantially different from that which some patients and doctors consider to be acceptable for other cancers. The goal of treatment in these patients is palliation. With currently available antiemetics and other supportive measures a short trial of carefully monitored treatment can be worth while in selected patients with symptoms.

CHRISTOPHER BRADLEY Senior Registrar PETER SELBY Professor

Yorkshire Cancer Research Campaign Institute for Cancer Studies,

St James's University Hospital,

Leeds LS97TF

1 Altman E, Cadman E. An analysis of 1539 patients with cancer of unknown primary site. Cancer 1986;57:120-4.

2 Gatter KC, Alcock C, Heryet A, Mason DY. Clinical importance of analyzing malignant tumours of uncertain origin with immunohistochemical techniques. Lancet 1985;ii:1302-5.

3 Horning SJ, Carrier EK, Rouse RV, Warnke RA, Michie SA. Lymphomas presenting as histologically unclassified neoplasms: characteristics and response to treatment. $f$ Clin Oncol 1989;7:1281-7.

4 Kagan AR, Steckel RJ. The limited role of radiological imaging in patients with unknown tumour primary. Semin Oncol 1991;18:170-3.

5 McMillan JH, Levine E, Stephens RH. Computed tomography in the evaluation of metastatic adenocarcinoma from an unknown primary site A rotrospective study Radiology 1982;143:143-6. Kirsten F, Chi CH, Leary JA, Ng ABP, Hedley DW, Tattersall MHN. Metastatic adeno or

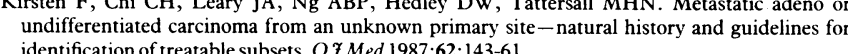

7 Le Chevalier T, Cvitkovic E, Caille P, Harvey J, Contesso G, Spielmann M, et al. Early metastatic cancer of unknown primary origin at presentation. A clinical study of 302 consecutive autopsied patients. Arch Intern Med 1988;148:2035-9.

8 Wadler S, Lembersky B, Atkins M, Kirkwood J, Petrelli N. Phase II trial of fluorouracil and recombinant interferon alfa-2a in patients with advanced colorectal carcinoma: an Eastern Cooperative Oncology Group study. F Clin Oncol 1991;9:1806-10.

9 Poon MA, O'Connell MJ, Moertel CG, Wieand HS, Cullinan SA, Everson LK, et al. Biochemical modulation of fluorouracil: evidence of significant improvement of survival and quality of life in patients with advanced colorectal carcinoma. F Clin Oncol 1989;7:1407-18.

10 Findlay M, Mansi JL, Ford HT, Nash AT, Cunningham D. Epirubicin, cisplatin and 5-fluorouracil (ECF) is highly effective in advanced gastric cancer. Eur f Cancer 1991;27(suppl 2):S71.

11 Sporn JR, Greenberg BR. Empiric chemotherapy in patients with carcinoma of unknown primary ite Am f Med 1990:88:49-55.

12 Milliken ST, Tattersall MHN, Woods RL, Coates AS, Levi JA, Fox RM, et al. Metastatic adenocarcinoma of unknown primary site. A randomised study of two combination chemotherapy regimens. Eur f Cancer Clin Oncol 1987;23:1645-8.

13 Strnad CM, Grosh WW, Baxter J, Burnett LS, Jones HW, Greco FA, et al. Peritoneal carcinomatosis of unknown primary site in women. A distinctive subset of adenocarcinoma. Ann Intern Med $1989 \cdot 111 \cdot 213-7$

14 Lee DJ, Rostock RA, Harris A, Kashima H, Johns M. Clinical evaluation of patients with metastatic squamous carcinoma of the neck with occult primary tumor. South Med f 1986;79:979-83.

15 Greco FA, Vaughn WK, Hainsworth JD. Advanced poorly differentiated carcinoma of unknown primary site: recognition of a treatable syndrome. Ann Intern Med 1986;104:547-53.

16 Hainsworth JD, Johnson DH, Greco FA. Poorly differentiated neuroendocrine carcinoma of unknown primary site: a newly recognized clinicopathologic entity. Ann Intern Med 1988;109: $364-71$

\section{Reconsidering compensation for medical accidents}

\section{Concentrate on those with the severest disabilities, whatever the cause}

No fault compensation is in retreat. The victors in the British election, the Conservatives, were the one major party that did not propose a no fault system for compensating medical accidents. The New Zealanders, who run a no fault scheme that has attracted international admiration, have just revised their scheme in a way that is likely to destroy it. The limited but successful schemes operating in Sweden and Finland are increasingly recognised not really to be no fault schemes, as they incorporate many notions that are close to fault. And there is a feeling-strongly expressed at a conference on alternative systems for compensating the victims of medical accidents held in Oxford earlier this month - that it may be better to concentrate resources on those who are severely disabled regardless of the cause of their disablement.

Almost nobody at the conference had a good word to say about tort as a means of compensating those injured in medical accidents. It is slow, capricious, and hugely wasteful of resources. Jeffrey O'Connell, professor of law at the University of Virginia, described it as offering "a ticket to a prize fight in which the victim gets punched by both sides." The aim in reforming the tort system must be, said Professor O'Connell, to shift the resources now wasted on transaction costs, compensating non-economic loss (pain and suffering), and duplicating funds met from collateral sources into the pockets of those who are severely injured. Most systemsincluding many no fault schemes-overcompensate the mildly injured and undercompensate the seriously injured. Professor O'Connell warned, however, about being too ambitious when trying to reform existing systems. He quoted the American senator Daniel Moynihan, who said, "We live in a world of competing sorrows" and pointed out that not all of those sorrows can be compensated.

One of the most difficult problems with no fault schemes is to define those events that should be compensated. Professor O'Connell described the failure of a Virginian scheme that aimed at compensating those children injured in birth accidents: the definition drawn up by a multidisciplinary team proved so exclusive that there has never been a successful claim. The New Zealand scheme, said Margaret Vennell from 